\title{
The current cyclone early warning system in Bangladesh: Providers' and receivers' views
}

Chandan Roy and Rita Kovordanyi

\author{
Linköping University Post Print
}

Tweet

N.B.: When citing this work, cite the original article.

Original Publication:

Chandan Roy and Rita Kovordanyi, The current cyclone early warning system in Bangladesh: Providers' and receivers' views, 2015, International Journal of Disaster Risk Reduction, (12), 285-299.

http://dx.doi.org/10.1016/j.ijdrr.2015.02.004

Copyright: Elsevier

http://www.elsevier.com/

Postprint available at: Linköping University Electronic Press

http://urn.kb.se/resolve?urn=urn:nbn:se:liu:diva-117927 


\title{
The Current Cyclone Early Warning System in Bangladesh: Providers' and Receivers' Views
}

\author{
Chandan $\operatorname{Roy}^{+}$(chandan.roy@liu.se or roychandan@live.com)*, Saroje Kumar Sarkar ${ }^{\#}$ \\ (sarojeu@yahoo.com), Johan Åberg ${ }^{+}$(johan.aberg@liu.se), and Rita Kovordanyi ${ }^{+}$ \\ (rita.kovordanyi@liu.se) \\ ${ }^{+}$Department of Computer and Information Science, Linkoping University, 58183 Linköping \\ \#Department of Statistics, Rajshahi University, Rajshahi 6205, Bangladesh
}

\begin{abstract}
Bangladesh has experienced several catastrophic Tropical Cyclones (TCs) during the last decades. Despite the efforts of disaster management organizations, as well as the Bangladesh Meteorological Department (BMD), there were lapses in the residents' evacuation behavior. To examine the processes of TC forecasting and warning at BMD and to understand the reasons for residents' reluctance to evacuate after a cyclone warning, we conducted an individual in-depth interview among the meteorologists at BMD, as well as a questionnaire survey among the residents living in the coastal areas. The results reveal that the forecasts produced by BMD are not reliable for longer than 12-hour. Therefore, longer-term warnings have to be based on gross estimates of TC intensity and motion, which renders the disseminated warning messages unreliable. Our results indicate that residents in the coastal areas studied, do not follow the evacuation orders due to mistrust of the warning messageswhich can deter from early evacuation; and insufficient number of shelters and poor transportation possibilities - which discourages late evacuation. Suggestions made by the residents highlight the necessity of improved warning messages in the future. These findings indicate the need for improved forecasting, and more reliable and more informative warning messages for ensuring a timely evacuation response from residents.
\end{abstract}

Keywords: accurate tropical cyclone forecasting; informative warning message; warning message interpretation; meteorologists' perspective; residents' perspective; principal component analysis

\section{Introduction}

Bangladesh is one of the most vulnerable countries for Tropical Cyclone (TC) induced disasters. Fourteen of the nineteen coastal districts of Bangladesh are high or moderate cyclone-risk areas $[1,2]$. These exposed districts are currently the home of around thirty and a half million people [3]. To ensure the safety of residents in the coastal areas, the Bangladesh government is investing considerable effort into developing a suitable approach to manage cyclone emergencies. As a result, residents' response to evacuation orders has improved considerably during the last decades [4-6]. Although residents' current evacuation response rate is still not satisfactory, further improvements could be difficult to achieve without resolving technical issues associated with early warnings as well as infrastructural problems (improved cyclone shelters, road communication, and housing) [4,7-9]. 
The success of an early warning system depends both on technical processes that turn meteorological data into warnings, and on human factors that transform warnings into actions [10-13]. In this article, we look at the cyclone early warning system in Bangladesh from two complementary perspectives:

1. How the Bangladesh Meteorological Department (BMD) forecasts TCs and disseminates warning messages.

2. How the residents in affected areas tend to react to warnings and evacuation orders.

Hence, we have collected data both from meteorologists at BMD and from residents in two coastal districts of Bangladesh, namely Bagerhat and Patuakhali, where the latter is a high cyclone-risk area and the former is a moderate-risk area, according to the cyclone-risk area classification proposed by Khan, Bhuyan, and Rahman [1].

\section{Background}

The Storm Warning Center (SWC) is a specialized unit of BMD, and is responsible for forecasting and issuing warnings for TCs in Bangladesh. BMD collects meteorological data through 35 ground-based, 10 weather balloon, 5 radar, and 3 rawinsonde stations. In addition, BMD receives weather satellite data, ocean-buoy-recorded meteorological, and sea surface data, and numerical-model-generated weather forecasts from other national and regional meteorological offices, as a member state of the World Meteorological Organization [14-16]. Currently, BMD employs two techniques: (a) Storm Track Prediction (STP), and (b) Steering and Persistence (STEEPER) for TC forecasting [17,18]. Technically, neither STP nor STEEPER is sufficiently advanced, and therefore cannot produce forecasts with good accuracy for more than 12 hours ahead [18].

\subsection{TC warning stages}

Low-pressure systems usually form deep south in the Bay of Bengal $(\mathrm{BoB})$ between $5^{\circ}$ and $15^{\circ}$ north latitudes, outside the coverage of radar $[19,20]$. To compensate for this, meteorologists at BMD use satellite images to monitor low-pressure systems over the bay. When a low-pressure system initially intensifies and sets a course towards north, meteorologists forecast its motion and intensity and issue an initial warning message. Through the issuance of the first warning, a Standing Order for Disaster (SOD) is initiated. The SOD provides guidelines for all the government agencies about the required state of readiness for responding to a probable TC attack [21,22]. After formation, TCs in the bay initially tend to move towards west or north-west and then set course towards north or northeast to finally make a landfall [23]. Due to this movement pattern, TCs frequently make landfall at the mid and east coast of Bangladesh.

Cyclone alert stage-This first stage is initiated at least 36 hours before a predicted landfall, when the speed of the rotating wind within a TC reaches $50 \mathrm{~km} / \mathrm{h}$ [23]. At this stage, $\mathrm{BMD}$ issues a cyclone alert message and informs the maritime ports, the river ports, and the media about the approaching TC. BMD also sends warning messages directly to the national coordination committee, the cyclone preparedness program, the relief and rehabilitation authorities and to the local administrations [14,23].

Cyclone warning stage - This second stage is initiated at least 24 hours before a predicted landfall, when wind speeds get between $51 \mathrm{~km} / \mathrm{h}$ and $61 \mathrm{~km} / \mathrm{h}$. A cyclone warning message is 
sent to the respective authorities and media, containing information about: (a) the current and forecasted position of the TC, (b) the TCs movement direction and rate of movement, (c) maritime ports and areas likely to be hit, (d) current maximum wind speed, (e) forecasted height of the storm surge, and (f) suggested safety measures for fishing boats [17].

Cyclone disaster stage-This stage is initiated at least 18 hours before landfall. If the maximum wind speed within the TC exceeds $61 \mathrm{~km} / \mathrm{h}$, a cyclone danger warning is issued, and an updated danger-warning message is disseminated every 30 minutes.

Cyclone great-danger stage-This last stage is initiated at least 10 hours before the predicted landfall. If the wind speed exceeds $89 \mathrm{~km} / \mathrm{h}$, a cyclone great-danger warning message is issued and the residents are urged to evacuate at this point [24]. Updates to a great-danger warning message are usually disseminated every 15 minutes.

BMD uses two separate signaling systems for the maritime and the river ports (and respective command areas) to convey the danger levels associated with TCs. An eleven-point signaling system, ranging from low to high danger level, is used for the maritime ports. In contrast, a four-point signaling system, ranging from low and high danger levels, is used for the river ports. In a warning message, the coastal districts located to the west of the Meghna estuary lie in the command area of Mongla maritime port, while the districts located to the east lie in the command area of Chittagong maritime port (Fig. 1).

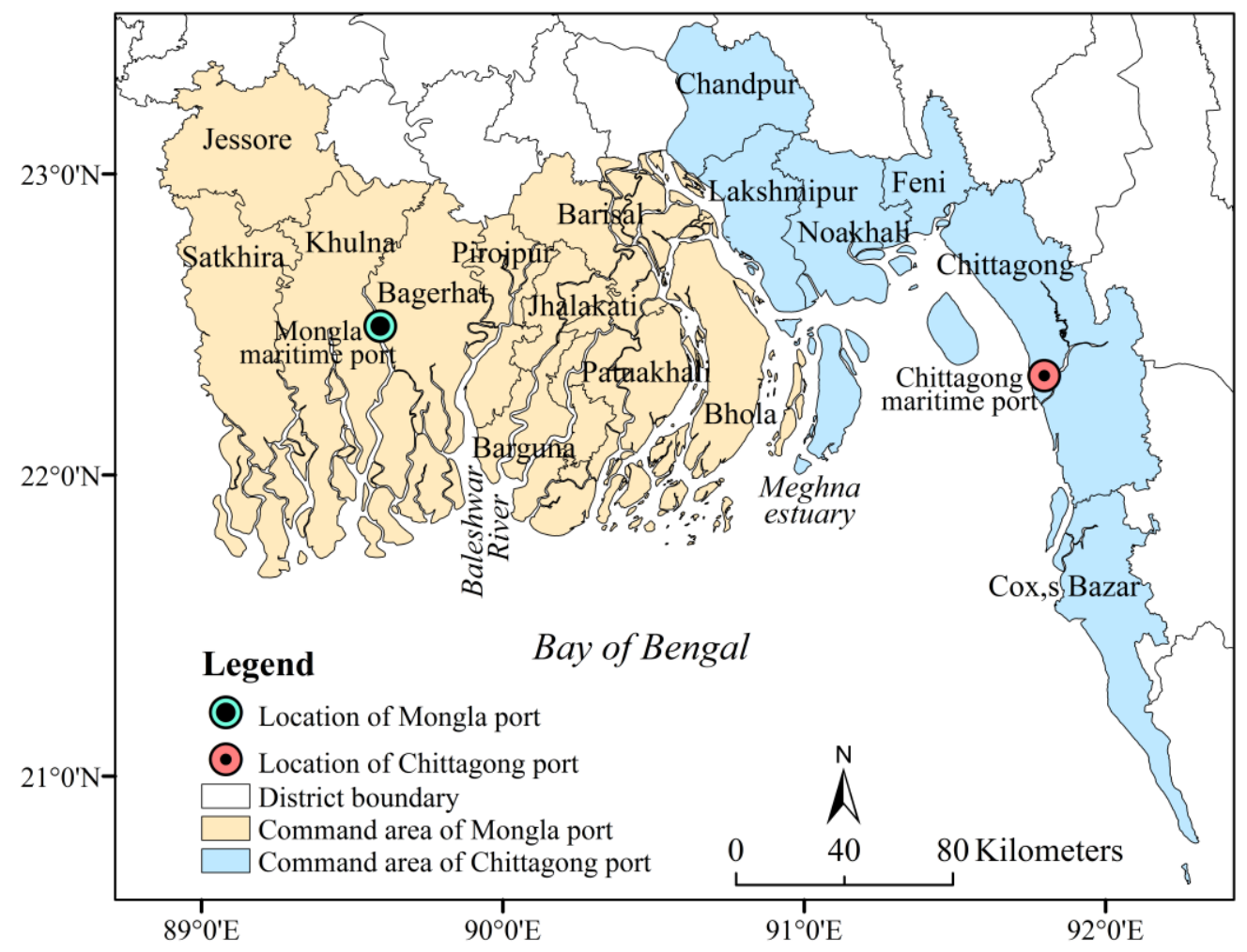

Fig. 1. Location of the maritime ports and their command areas.

\subsubsection{New methods for warning message dissemination}

The Bangladesh Department of Disaster Management (DDM) has recently developed three mobile-network-based warning message dissemination methods in order to make warning 
messages easily accessible to the coastal residents and field-level disaster management committees [21]:

1. Cell Broadcasting System can be used to send warning messages to a targeted population group that is, residents in the coastal areas.

2. Interactive Voice Response is a method where residents can listen to a recorded warning message by calling a number.

3. Short Message Service is a text messaging service, which is specially designed for field-level disaster management committees. Members of these committees continuously receive updated information about the approaching TC on their mobile phones in cyclone emergencies.

\subsection{Response behavior}

Human naturalistic decision making is based on previous experience with situations that are similar to the current one $[25,26]$. Typically, a decision is made directly, without comparison with possible alternative actions: As long as the current decision seems workable, alternatives are not evaluated. Research also shows that decisions are to a large extent guided by affectpositive or negative emotions that are triggered by the current situation, because of its likeness with previous experience [27].

There is an important temporal aspect in decision making: a response can gain in value as evidence motivating it amasses over time [28]. For example, given a basic unreliability of early, long-term meteorological forecasts, a decision to evacuate might seem disadvantageous at first, considering the risks involved with leaving one's house and property unguarded. As time unfolds and the forecast becomes more certain, a decision to evacuate can gain in value. However, at this later point, other risk factors can come into play, for example, that the chosen shelter is too far, which could leave the resident exposed on the road to the shelter, or that the shelter is full, which would, again, leave the resident exposed.

To complicate matters, recipients of the warning messages tend to respond not as isolated individuals; instead, their reactions have to be seen in the context of interactions with other people. So what can be seen as response from people living in a community is mostly a group or collective product, rather than an individual's isolated reaction $[29,30]$. In this way, community response to warning is a function of both individual judgment and communal social confirmation [31-34].

Moreover, the contents of a warning message might not be considered in the same way by its provider and by its receivers living in a community [10]. Results from recent studies conducted on the offshore islands and in the coastal regions of Bangladesh show that people often refrain from responding to the warning messages, typically for the following reasons:

1. People do not receive, understand or believe the warning, in the latter case partly because the warning messages are seen as unreliable[4,6,7,35].

2. The guidelines for evacuation contained in the messages are not clear $[4,36,37]$.

3. The shelters are far from the residents' homes, do not have enough capacity, or are derelict due to lack of maintenance [4,7,38].

4. Underlying causes of vulnerability to TC, such as lack of access to resources, lack of education and training, fragmentation in the community $[31,38]$. 
Previous research evaluating the cyclone early warning system in Bangladesh has only considered the residents' perspective: the residents' perception of risk, their vulnerability to TCs, their indigenous coping strategies and their response to warnings $[5,9,34,36,39]$. The process of TC forecasting and warning at BMD, which notably plays an important role in cyclone early warning, has remained unaddressed. However, the quality of the information contained in a warning message is dependent on the quality of the produced forecasts. Therefore, eliciting the meteorologists' views on TC forecasting and warning is equally important for evaluating the efficiency of a cyclone early warning system as is studying residents' reactions to warnings $[12,13,29,40,41]$.

In this paper, we attempt to shed light on the insufficiencies of the currently operational cyclone early warning system in Bangladesh by looking at potential problems from both a producer (meteorologists) and a receiver (residents) perspective.

\section{Method}

The forecasted intensity level of a TC might influence the actions taken by the residents $[29,42-44]$, so to avoid biased results, we collected data about two different historical TCs with different intensities, namely the severe TC Sidr and the less severe Mahasen. A research team of three members, including the first author, collected data through an in-depth interview with the meteorologists at BMD and a questionnaire survey administered among the residents in the coastal areas.

In-depth interviews are considered to be suitable for collecting detailed information from relatively few respondents in the case of evaluating a socio-technical system [12,45-48] employed this method to collect information on TC forecasting and warning from the meteorologists at BMD. Questionnaire surveys in contrast, are commonly used for: (a) classifying a population on desired bases, such as age, occupation, and housing condition; (b) assessing people's opinion regarding a particular issue or issues; and (c) collecting information related to people's behavior [39,49-52]. We therefore chose to conduct a questionnaire survey among the residents in the coastal areas.

\subsection{In-depth interview among warning message providers}

The aim of the interview at BMD was to collect information about the currently operational TC forecasting and warning system, so that the reasons for disseminating imprecise and uninformative warnings could be identified.

\subsubsection{Participants}

We interviewed three meteorologists at BMD. The meteorologists were between 41 and 53 years of age and had all been working at BMD for more than 10 years. Two of the three meteorologists had a background in physics and one had a background in mathematics.

TC forecasting is a non-routine activity that the meteorologists perform during cyclone emergencies, in addition to their everyday work. As SWC is solely responsible for monitoring, forecasting, and disseminating warnings for TCs in Bangladesh, we chose to interview meteorologists only from this unit. Becoming an expert in an area of meteorology requires both educational background and many years of work experience. As none of the SWC meteorologists had meteorological or other atmosphere-related background, we only 
interviewed those meteorologists who had long work experience (at least ten years) in TC forecasting. This selection criterion limited the number of participants to three at BMD.

\subsubsection{Data collection}

A battery of structured and open-ended questions was used for the interview. The three respondents were interviewed individually. Structured questions were used to elicit meteorological data collection and use for TC forecasting, forecast length, forecast error, and cooperative activities across agencies. We also collected all the warning messages that were disseminated during both of the studied TCs to get a better understanding of how warning messages are formulated. Open-ended questions were used to understand the: (a) methods used for atmospheric data analysis, (b) processes of TC track and intensity prediction, (c) processes of warning message formulation and dissemination, (d) perceived limitations of the existing TC forecasting and warning system, and (e) meteorologists' views on future development plans.

We asked all the questions orally and the meteorologists deliberated their opinions on the questions orally. We took notes both of the meteorologists' answers for the structured questions and their opinion on the open-ended questions. We also conducted a short followup interview among the same three meteorologists, where we asked them to draw a flowchart describing the processes of TC forecasting at BMD.

\subsubsection{Analysis}

The answers from the meteorologists were analyzed using a method based on deductive thematic analysis $[53,54]$. As we were interested in five specific questions (see a-e items in section 3.1.2), only the features that could be used for answering these questions were coded during the thematic analysis.

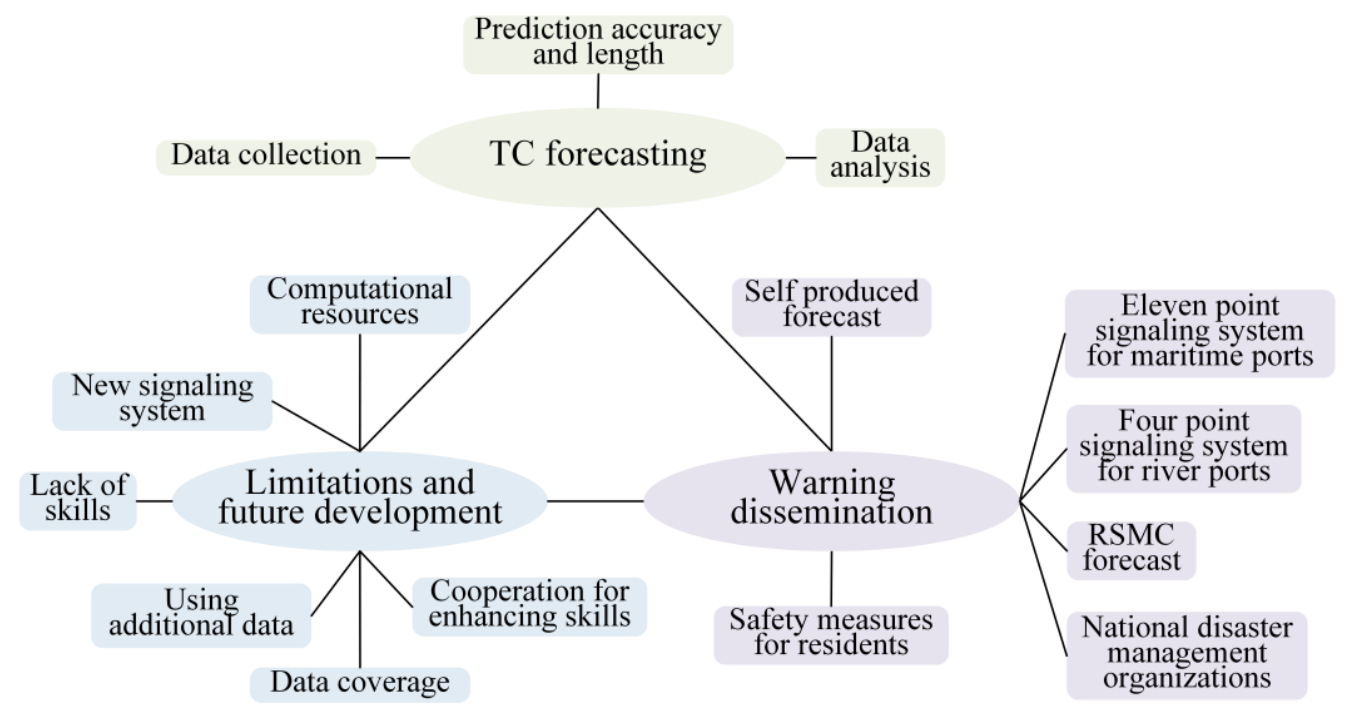

Fig. 2. Thematic map showing three final themes (marked using ellipses) and relevant codes (marked using rectangles).

Three themes were then identified using a semantic approach [55]. The codes were assigned to the themes based on their relevance to the three themes, to produce a thematic map (Fel! Hittar inte referenskälla.). The TC forecasting flowcharts depicted by the three meteorologists contained variations. As we wanted to produce a complete flowchart that 
would represent the processes of $\mathrm{TC}$ forecasting system at $\mathrm{BMD}$, we combined the three flowcharts, also taking into account the responses made by the meteorologists during the interview, which is presented in section 4.1 under results.

\subsection{Questionnaire survey among warning message receivers}

A wide range of individual and societal factors can influence residents' response to a warning message. The present work has assessed residents' response to warnings, but used accuracy of forecast and warning message content and response as the main points of discussion.

\subsubsection{Geographical area}

Of the two selected TCs, Mahasen made landfall at Bhola (the mid coast of Bangladesh, which is frequently affected by TCs), while Sidr made landfall at the Baleshwar river (the

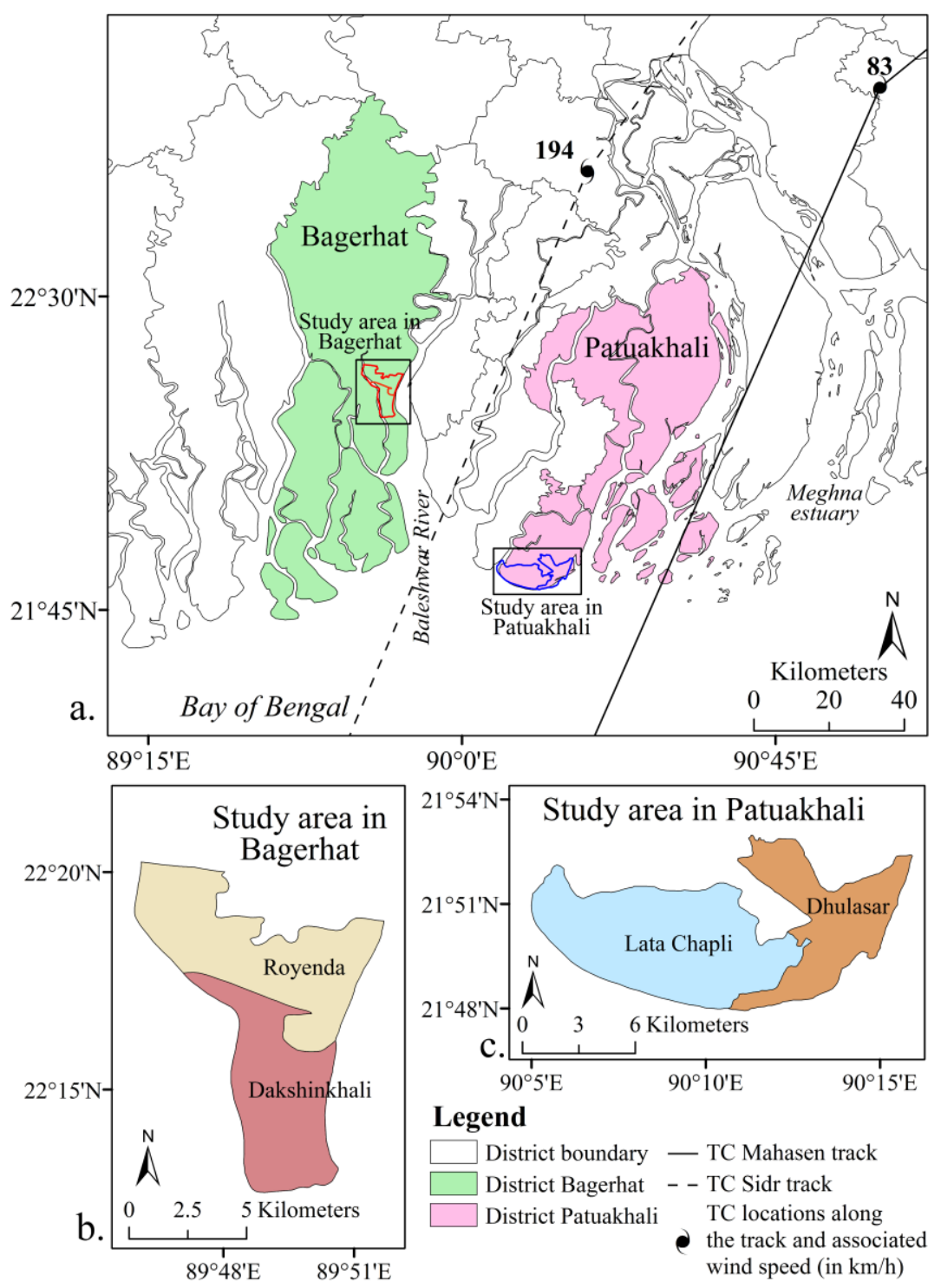

Fig. 3. a. Points at which TC Sidr and Mahasen crossed the coastline, b. studied unions in Bagerhat, and c. studied unions in Patuakhali.

west coast of Bangladesh, where TC landfall frequency is low) [56]. In order to increase the external validity and generalizability of the findings of the survey, the survey was 
administered among residents living in both medium- and high-cyclone-risk areas. For this reason, the moderate cyclone-risk area Bagerhat and the high cyclone-risk area Patuakhali were selected for this study (Fig. 3).

In addition to Bagerhat, we chose Patuakhali (instead of Barguna, cf. [1]) from the high cyclone-risk areas, as it borders directly with the BoB. Through this study area selection, we could consider the variations in residents' response to warnings that might occur with the degree of exposure to TCs due to nearness to the sea as well as due to TC landfall pattern in the coastal region of Bangladesh.

The two chosen districts, Patuakhali and Bagerhat, comprise 72 and 75 unions (small administrative units), respectively. We used simple random sampling to select two unions from Bagerhat, namely Royenda and Dakshinkhali, and two unions from Patuakhali, namely Dhulasar and Lata Chapli, for the data collection (Fel! Hittar inte referenskälla.).

\subsubsection{Participants}

The primary sampling units were individual households. Lists of all the households in the four selected unions were collected from the respective union parishads (union administrative offices) prior to administering the survey. Fifty households from each union were selected using simple random sampling without replacement.

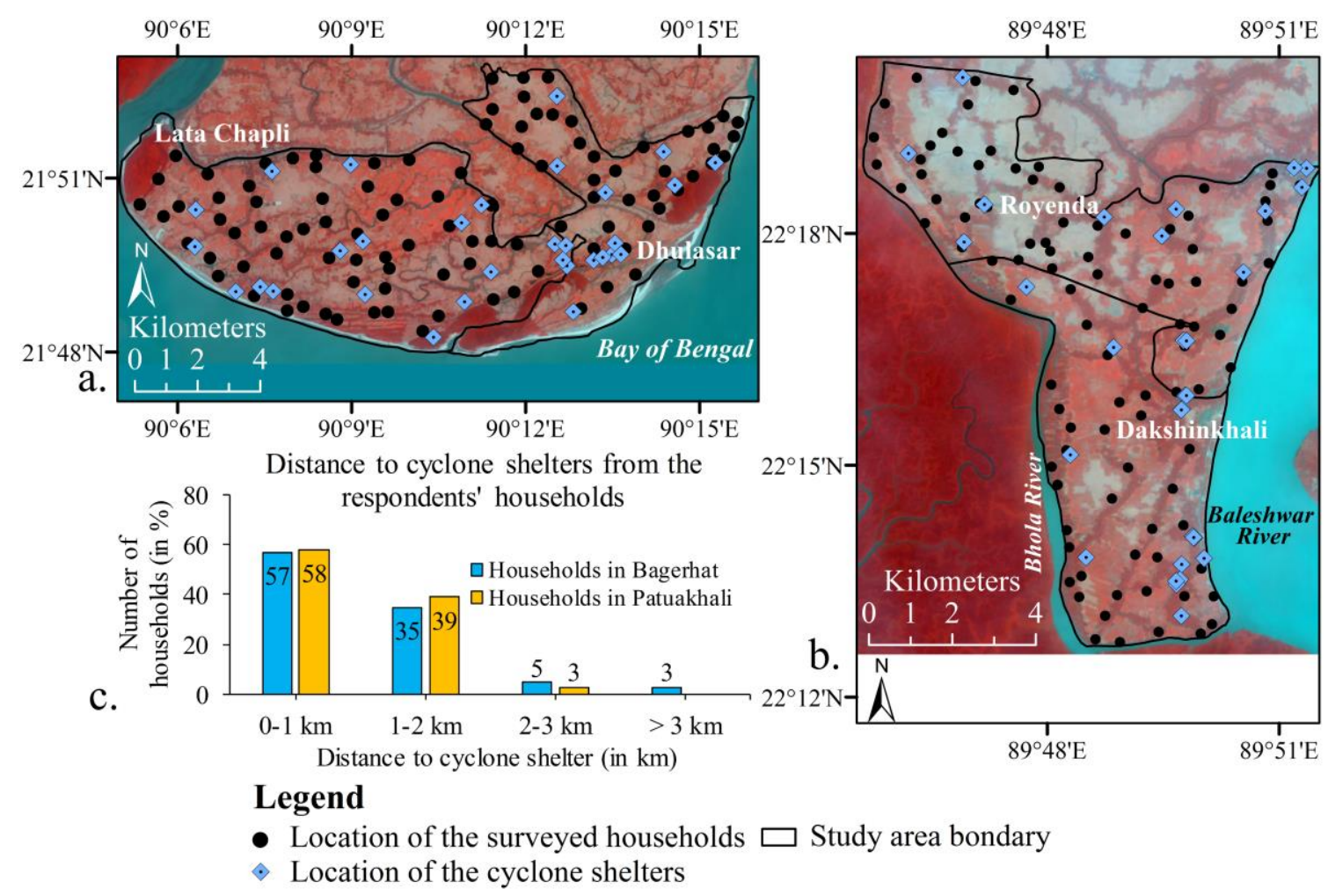

Fig. 4. GPS positions of the respondents' households and cyclone shelters, a. in Patuakhali and b. in Bagerhat. c. Illustrates percentages of the respondents' households that are located within one, two, three, or out of three kilometers of a cyclone shelter.

Note: Images in the background are false-color composites of Landsat- 8 image bands acquired on $26^{\text {th }}$ February, 2014. 
The data were collected from adult persons in each household using the questionnaire described in the next section. In total, 200 respondents participated from the four selected unions in two districts. During the survey, we also recorded the geographic position of each respondent household using GPS and used these positions to calculate the distances to the shelters (Fig. 4).

\subsubsection{Data collection}

The questionnaire used to elicit respondents' views on the current cyclone early warning system consisted of two parts. The first part contained structured questions for socioeconomic information. The second part of the questionnaire contained multiple-choice questions and elicited respondents' views on TC warnings.

To start with, we asked the respondents about their views on the media currently used for warning dissemination. We also asked whether the respondents followed the evacuation orders and the reasons for their decision at this point. Then, to get insight into respondents' ability to interpret warning messages, we used four pre-recorded warning messages (two for each of the two TCs Sidr and Mahasen). After letting the respondents listen to the warning messages, we asked them to describe the information contained in the messages and to highlight the differences between the two warning messages for the same TC. At the end, we asked the respondents to express their satisfaction level with the disseminated warnings for TCs Sidr and Mahasen on a five-point scale (where points 1 and 5 indicate dissatisfied and satisfied at a very high level, respectively). Respondents were also asked if they could suggest ways to improve TC warnings in the future.

For each multiple-choice question, respondents were allowed to make multiple responses. Also, they could express additional comments and views in free text at the end of each question. As the survey involved listening to pre-recorded warning messages by the respondents and as the respondents might have difficulties in understanding all the questions, the survey team members asked all the questions orally and noted the responses themselves for each of the 200 respondents.

\subsubsection{Analysis}

Frequency distribution and range (a descriptive statistical technique) were used to analyze the socio-economic information obtained in the first part of the questionnaire. Several statistical techniques: multiple-response analysis, frequency distribution, binary logistic regression, dimension reduction using Principal Component Analysis (PCA), and cross tabulation were used to analyze the answers obtained in the second part of the questionnaire.

Multiple-response analysis is considered to be suitable for revealing response patterns when respondents' views are captured using multiple-choice questions [57,58]. Therefore, it was used to reveal the participants' response patterns associated with: (a) the media through which they received warning messages during the two TCs, (b) media through which they would like to receive warning messages, (c) reasons for preferring those media, (d) reasons for selecting the warning satisfaction level, and (e) suggestions for improving warning messages in the future. The participants' response pattern for each of these questions was analyzed separately. As responses were calculated individually for each multiple-choice option under a question, the multiple-choice option selected by the greatest number of participants ultimately scored the highest percentage and options selected by fewer 
participants scored lower percentages. The participants were allowed to choose several options under each question, therefore, the sum of all multiple-choice options could be more than $100 \%$.

The media's efficiency for warning message dissemination was solved using binary logistic regression analysis. The respondents' ability to correctly interpret the warning message contents was measured using frequency distribution. The reasons for non-evacuation were extracted through dimension reduction using PCA.

PCA is a technique for capturing the co-variation among high-dimensional data, allowing the data to be described using a lower number of aggregate dimensions than the original data set. The variables in the original data set corresponded to the individual questions, eliciting the reasons for non-evacuation, that were administered in the survey. Each data point in this high-dimensional space would then reflect an individual respondent's answers to these questions. The aim of PCA was to find out if respondents' answers for some of these questions tended to co-vary, as this would be an indication that several questions were tapping into the same cognitive or behavioral concept. For sets of questions where respondents' answers co-varied, it would make sense to treat these as abstract, underlying reasons that were controlling residents' behavior.

Finally, we determined the correlation between two or more variables (socio-economic status, reception of warning and response to warning) by calculating their cross products. All the statistical analyses were done separately for each of the two unions in the two districts so that the residents' responses could be compared.

\section{Results elicited from meteorologists}

In the following three subsections, we describe the results of the interview with the meteorologists at BMD. Each of the three subsections corresponds to one of the three themes that were identified during thematic analysis of the data (see section 3.1.3).

\subsection{TC forecasting at BMD}

The TC forecasting technique that the meteorologists are currently using is a combination of three TC forecasting techniques: (a) steering airflow determination [59], (b) averaging across historical TCs [60], and (c) climatology and persistence [61]. Instead of combining the outputs from these three techniques (hybrid forecasting technique ${ }^{1}$ ), the meteorologists take advantage of each technique separately. Ultimately, they produce TC track and intensity forecasts relying on their expert knowledge. The TC forecasting flowchart we obtained in the follow-up interview provides a good overview of TC forecasting at BMD (Fig. 5).

The meteorologists at BMD forecast TCs in three consecutive steps:

1. Step 1 (collection, interpolation, and analysis of wind data): Once the wind direction and speed data are available from ground observations, together with upper-level atmospheric data from weather balloons, these data are interpolated and plotted on a map to produce continuous fields of wind-direction and wind-speed information. The

\footnotetext{
${ }^{1}$ Hybrid forecasting techniques combine the output from two or more techniques using statistical methods to produce TC forecasts.
} 
current and recent past positions of the TC obtained from satellite and Doppler radar observations are also plotted on the same map. These wind data are analyzed using Buys Ballot law [62] to better understand the synoptic conditions associated with the TC.

2. Step 2 (determination of the steering airflow): Wind direction and speed at an air pressure level that correlates best with the TC's movement direction and speed, also known as steering level is identified through comparing the wind information within the TC vortex with surrounding wind speeds and directions at various pressure levels.

3. Step 3 (forecasting TC track and intensity): The TC's current and recent motion and speed are extrapolated taking the steering wind flow into account to estimate the TC's future movement direction and speed (steering and persistence technique). The movement direction and speed of the current TC are compared to that of previous TCs in the $\mathrm{BoB}$ that had a similar formation date, location of origin, and exhibited similar movement characteristics, for identifying suitable historical analogues. The current TC's future movement direction and intensity are estimated through averaging the motion and intensity characteristics of these historical analogues (averaging across $T C s$ ), as well as through relating the current TC's recent movement direction and intensity to that of historical analogues using regression (climatology and persistence technique). Meteorologists at BMD rely on their expert knowledge when they combine the output of the three techniques to forecast TC track and intensity.

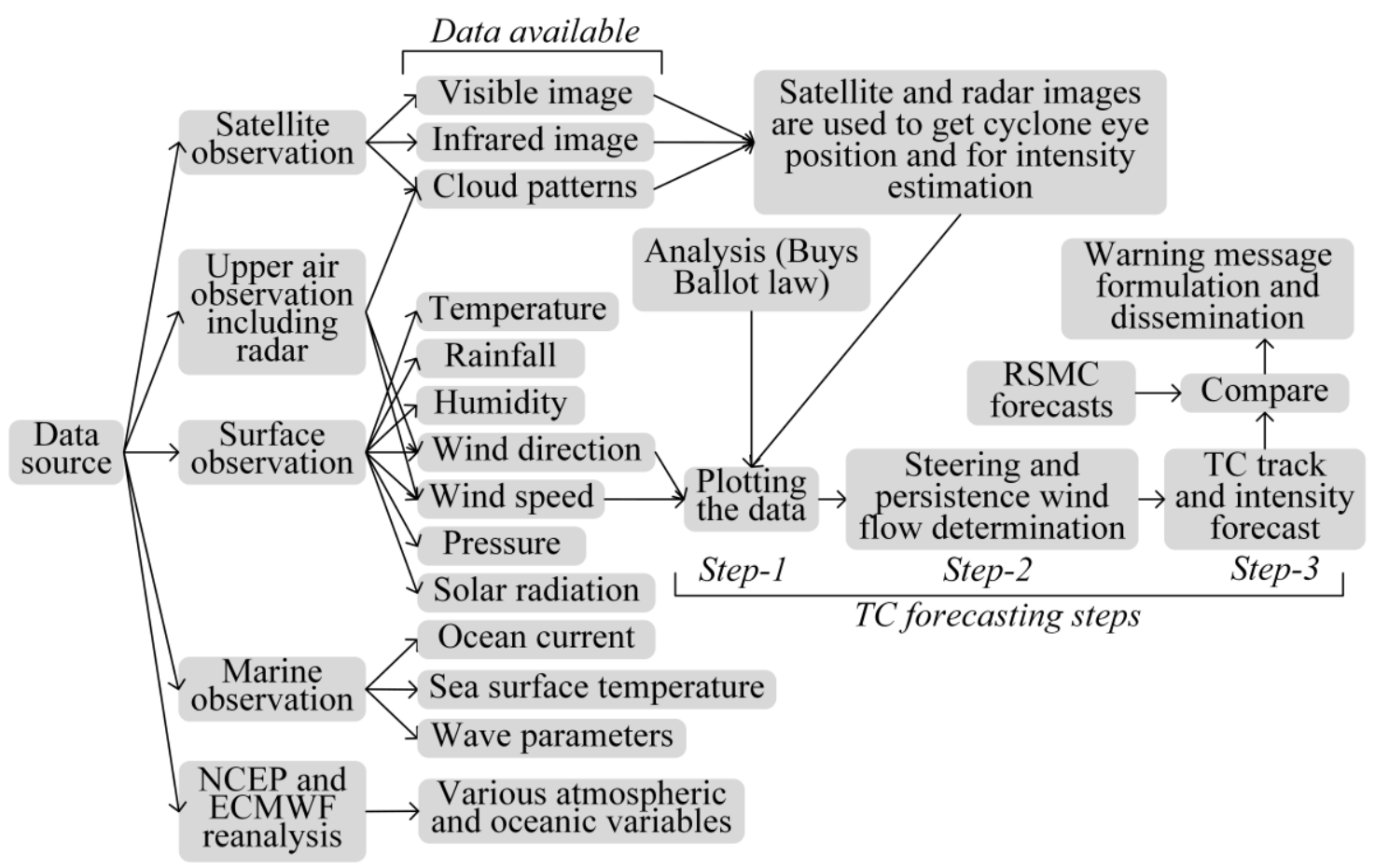

Fig. 5. The basic flowchart of TC forecasting at BMD.

\subsection{Formulation and dissemination of warning messages}

The meteorologists at BMD formulate warning messages based both on self-produced and numerical-model-generated forecasts received from the Regional Specialized Meteorological Center (RSMC) in India, with most of the weight on self-produced forecasts. In cyclone emergency situations, BMD disseminates new warning messages as special weather bulletins 
at every three to six hours, depending on the severity and motion characteristics of the approaching TC $[63,64]$. BMD disseminated 29 special warning bulletins during the 6-day lifespan of TC Sird and 35 special warning bulletins during the 7-day lifespan of TC Mahasen. In each bulletin, information was added, changed, or deleted depending on the changes in forecasted TC track and intensity.

BMD issues warning messages for the maritime and the river ports following a system that was introduced during the British colonial period. In a warning message, the same signal (danger level) is issued for the maritime ports and their command areas (see Fig. 1). This division results in coarse and non-adaptive warnings at the borders, where neighboring areas belonging to different jurisdictions could receive widely disparate warning messages.

During the British colonial period, the coastal region of Bangladesh was sparsely populated and TC warnings were mainly used for ocean-going vessels. Therefore, it was not necessary to include safety measures for coastal residents in the issued warning messages at that time. As this century-old system is still in use, warning messages issued by BMD during the TCs Sidr and Mahasen did not contain any recommended safety measures for the residents $[63,64]$. Safety measures for the residents are added later following the guidelines prepared by DDM (Department of Disaster Management) [24].

\subsection{Limitations and future development plans}

Technical and organizational limitations can impede accurate TC prediction at BMD:

1. Infrequent data updates over the BoB: Though storm locations are regularly available from satellite and radar images, and ground-based observations are available every 6 hours, steering wind information is only available every 12 hours. Moreover, both ground-level and upper-level atmospheric data over the BoB are often missing. In such situations, meteorologists use 12-hour old and interpolated values of wind direction and speed over the BoB as input to TC forecasting.

2. Data integration problems: BMD receives ocean buoy data and reanalysis data from the National Centers for Environmental Prediction (NCEP) [65]. However, BMD cannot use these data to compensate for the infrequent update of data over the $\mathrm{BoB}$, as the received data are often in formats that are not supported by the currently operational forecasting techniques, and the meteorologists at BMD do not have the necessary expertise to re-code the data.

3. Forecast verification: With no benchmarking technique (such as CLIPER and SHIFOR [66]) in operation, the meteorologists are not able to verify prediction performance of the current TC forecasting technique. As a result, they cannot include the precision level of the produced forecast in the warning message.

4. Lack of expertise: BMD has access to numerical models to produce forecasts for rainfall and storm-surges. However, these models are not advanced and the meteorologists do not have the necessary data-processing knowledge and computational skills to modify these models to produce forecasts for new atmospheric phenomena like TCs.

5. Lack of computational resources: The BMD is running forecasts on a cluster computer using 15 quad-cores running at $2.8 \mathrm{GHz}$ each, with 16 gigabytes of RAM. These computational resources are insufficient for running advanced numerical models $[67,68]$. 
The meteorologists at BMD wish to enhance forecast accuracy and extend forecast length so that they can provide precise and detailed information about TCs in the warning messages. They have identified a number of directions where they want to develop in the future:

1. Use new data such as ocean buoy data, NCEP reanalysis, and the European Centre for Medium-Range Weather Forecasts (ECMWF) reanalysis [69] for TC forecasting.

2. Deploy the hurricane-forecasting version of the Weather Research and Forecasting (HWRF) model for precise long-term TC track and intensity forecasts [70]. As BMD is already running WRF for forecasting rainfall, it would be easy for the meteorologists to adopt HWRF compared to other numerical models.

3. Scale up the computational resources.

4. Train further to allow the meteorologists to handle numerical weather prediction models.

5. Deploy the generalized eight-point TC signaling system [24] for both river and maritime ports.

6. Collaborate with other organizations for technical and intellectual cross-fertilization.

\section{Results elicited from residents}

The respondents' socio-economic profile was almost the same in both study areas. In both of the study areas Bagerhat and Patuakhali, around $70 \%$ of the respondents were male and $30 \%$ were female. All the respondents in Bagerhat and Patuakhali were between 18 and 84 years of age. In Bagerhat, respondents were involved in farming (21\%), fishing (11\%), service $(9 \%)$, business $(8 \%)$, and in multiple occupations (36\%) like farming, fishing, and construction work for their livelihood, and the remaining $15 \%$ were dependent on head of the family. In Patuakhali, the occupation pattern was almost the same as in Bagerhat. Of the respondents, $28 \%$ were involved in agriculture, $15 \%$ in fishing, $10 \%$ in business, $5 \%$ in service, and 34\% were involved in multiple occupations for their livelihood, and the remaining $8 \%$ were dependent. Most of the surveyed households in Bagerhat $(76 \%)$ and in Patuakhali $(80 \%)$ consisted of 3 to 6 family members. More than $85 \%$ of the surveyed households in both of the districts were katcha (floor of mud, wall of wood/tin/hay, roof of tin/hay). In Patuakhali, $86 \%$ of the respondents had mud-built roads surrounding their home. For Bagerhat this number was $66 \%$.

\subsection{Reception and interpretation of the warning messages}

In Bagerhat, most of the respondents received warning messages during both of the TCs (83\% during Sidr and 93\% during Mahasen). The reasons for not receiving warning messages by the rest of the respondents were: (a) lived in remote areas, therefore could not be reached by megaphones, and/or (b) did not have access to radio or television. Of the respondents who received warning messages during the TCs, $76 \%$ were reached by megaphone messages, $73 \%$ were reached through radio and/or television, $21 \%$ were reached by signal flag, $4 \%$ received the message from other persons, and $2 \%$ read it in a newspaper (multiple responses were possible).

The warning dissemination media preferred by the respondents correspond well to the media that they received warning messages from during the studied TCs. The respondents would have liked to receive warnings through megaphone $(60 \%)$, electronic media $(57 \%)$, and signal flag (5\%) (multiple responses were possible). No respondent preferred to receive 
warnings through newspapers and from other persons. The reasons for preferring megaphone and electronic media to other media by the respondents were: $60 \%$ found megaphone messages dependable and easily understandable; $50 \%$ found electronic media immediate, dependable and easily understandable; and only $9 \%$ found signal flags easily understandable and dependable (multiple responses were possible).

In Bagerhat, the use of electronic media was significantly important $(p=0.002)$ for dissemination of warning messages among the respondents during Sidr. However, during Mahasen, both electronic media and megaphone played a significant role $(p=0.004)$ in warning message dissemination. Other media, like newspapers, messages from other persons, and the use of signal flags did not contribute significantly to the dissemination of warning messages during the two TCs. Electronic media's highest odds ratio (6.247) also establishes this media as the most effective among all warning dissemination media. This implies, the chance of being reached by a warning message in Bagerhat is greater than not getting a warning message if the message is disseminated through electronic media compared to other media. Reception of warnings during Sidr was significantly related to respondents' gender ( $p$ $=0.017, \mathrm{~F}=5.926)$ and occupation $(\mathrm{p}=0.001, \mathrm{~F}=11.082)$. In contrast, reception of warnings during Mahasen was not effected by gender and socio-economic status.

Almost all the respondents in Patuakhali (98\%) received warning messages during both of the TCs. Among the respondents who received warning messages during the TCs, $82 \%$ received them through megaphone, 63\% through electronic media, 40\% through other persons, $8 \%$ through signal flag and only $2 \%$ through newspaper (multiple responses were possible). As in Bagerhat, the media preferred by the respondents in Patuakhali also match the media through which they received cyclone warnings.

The respondents preferred to receive warnings through electronic media (57\%), megaphone (53\%), signal flag (4\%), and newspapers (2\%) (multiple responses were possible). However, no respondent desired to receive warning messages from other persons. The reasons for respondents to prefer electronic media and megaphone to other media were that respondents found electronic media (58\%) and megaphone (56\%) easily understandable and more dependable than signal flags (3\%) and newspapers (2\%) (multiple responses were possible). The type of media had no effect on warning message dissemination efficiency during any of the TCs in Patuakhali. We did not find any significant relationship between socio-economic status in Patuakhali and being successfully reached by warning messages.

\subsubsection{Warning message interpretation}

The extent to which respondents are capable of understanding the information contained in a warning message usually governs their response to warning [10,40]. As warning message contents typically varies depending on the TC's forecasted track and intensity, the ability to identify these variations is also important for the respondents' safety. The extent to which the respondents were able to understand the information after listening to our prerecorded messages are presented in Table 1 for Bagerhat and in Table 2 for Patuakhali. The respondents could extract most of the information contained in the warning messages correctly. However, misinterpretation rates were high for information on: "forecasted movement direction", "time of landfall", and "surge height" (marked using boldface numbers in the tables) compared to other information, like TC's current location and danger level in 
the warning messages. Respondents also found it difficult to spot the differences between two warning messages for the same TC (columns 4 and 7 in the tables).

Table 1 Correct warning message interpretation by the respondents in Bagerhat

\begin{tabular}{|c|c|c|c|c|c|c|}
\hline \multirow{3}{*}{$\begin{array}{l}\text { Information } \\
\text { in the } \\
\text { warning } \\
\text { messages }\end{array}$} & \multicolumn{3}{|c|}{ Sidr warning messages } & \multicolumn{3}{|c|}{ Mahasen warning messages } \\
\hline & $\begin{array}{l}\text { Special } \\
\text { bulletin No. } \\
5 \text { on } 12 \\
\text { Nov. } 2007\end{array}$ & $\begin{array}{l}\text { Special } \\
\text { bulletin No. } \\
25 \text { on } 15 \\
\text { Nov. } 2007\end{array}$ & $\begin{array}{l}\text { Change in } \\
\text { information }\end{array}$ & $\begin{array}{l}\text { Special } \\
\text { bulletin No. } \\
8 \text { on } 12 \\
\text { May } 2013\end{array}$ & $\begin{array}{l}\text { Special } \\
\text { bulletin No. } \\
30 \text { on } 16 \\
\text { May } 2013\end{array}$ & $\begin{array}{l}\text { Change in } \\
\text { information }\end{array}$ \\
\hline & \multicolumn{3}{|c|}{ Percentage of the respondents } & \multicolumn{3}{|c|}{ Percentage of the respondents } \\
\hline $\begin{array}{l}\text { Current TC } \\
\text { location }\end{array}$ & 92 & 93 & 79 & 91 & 94 & 83 \\
\hline $\begin{array}{l}\text { Forecasted } \\
\text { movement } \\
\text { direction }\end{array}$ & 73 & 79 & 49 & 78 & 75 & 51 \\
\hline Danger level & 96 & 97 & 96 & 94 & 99 & 95 \\
\hline $\begin{array}{l}\text { Ports/Areas } \\
\text { likely to be } \\
\text { affected }\end{array}$ & 81 & 94 & 47 & 87 & 95 & 53 \\
\hline $\begin{array}{l}\text { Time of } \\
\text { landfall }\end{array}$ & 51 & 87 & 57 & 63 & 89 & 54 \\
\hline Wind speed & 85 & 96 & 78 & 88 & 97 & 81 \\
\hline Surge height & 49 & 94 & 82 & 55 & 96 & 84 \\
\hline $\begin{array}{l}\text { Safety } \\
\text { guidance for } \\
\text { fishing boats }\end{array}$ & 77 & 88 & 39 & 82 & 90 & 31 \\
\hline
\end{tabular}

Table 2 Correct warning message interpretation by the respondents in Patuakhali

\begin{tabular}{|c|c|c|c|c|c|c|}
\hline \multirow{3}{*}{$\begin{array}{l}\text { Information } \\
\text { in the } \\
\text { warning } \\
\text { messages }\end{array}$} & \multicolumn{3}{|c|}{ Sidr warning messages } & \multicolumn{3}{|c|}{ Mahasen warning messages } \\
\hline & $\begin{array}{l}\text { Special } \\
\text { bulletin } \\
\text { No. } 5 \text { on } 12 \\
\text { Nov. } 2007\end{array}$ & $\begin{array}{l}\text { Special } \\
\text { bulletin } \\
\text { No. } 25 \text { on } \\
15 \text { Nov. } \\
2007\end{array}$ & $\begin{array}{l}\text { Change in } \\
\text { information }\end{array}$ & $\begin{array}{l}\text { Special } \\
\text { bulletin } \\
\text { No. } 8 \text { on } 12 \\
\text { May } 2013\end{array}$ & $\begin{array}{l}\text { Special } \\
\text { bulletin } \\
\text { No. } 30 \text { on } \\
16 \text { May } \\
2013\end{array}$ & $\begin{array}{l}\text { Change in } \\
\text { information }\end{array}$ \\
\hline & \multicolumn{3}{|c|}{ Percentage of the respondents } & \multicolumn{3}{|c|}{ Percentage of the respondents } \\
\hline $\begin{array}{l}\text { Current TC } \\
\text { location }\end{array}$ & 97 & 98 & 88 & 97 & 98 & 90 \\
\hline $\begin{array}{l}\text { Forecasted } \\
\text { movement } \\
\text { direction }\end{array}$ & 72 & 97 & 43 & 70 & 97 & 42 \\
\hline Danger level & 97 & 100 & 94 & 98 & 100 & 95 \\
\hline $\begin{array}{l}\text { Ports/Area } \\
\text { likely to be } \\
\text { affected }\end{array}$ & 78 & 98 & 53 & 81 & 100 & 51 \\
\hline $\begin{array}{l}\text { Time of } \\
\text { landfall }\end{array}$ & 50 & 96 & 41 & 45 & 95 & 39 \\
\hline Wind speed & 92 & 100 & 87 & 90 & 100 & 85 \\
\hline Surge height & 65 & 99 & 91 & 64 & 99 & 87 \\
\hline $\begin{array}{l}\text { Safety } \\
\text { guidance for } \\
\text { fishing boats }\end{array}$ & 95 & 100 & 42 & 93 & 100 & 48 \\
\hline
\end{tabular}




\subsection{Response to warnings}

In Bagerhat, $28 \%$ of the respondents evacuated during Sidr (2007). This number increased to 43\% during Mahasen (2013), which notably, was a less severe TC. This means that about half of the respondents did not follow the evacuation orders even after receiving cyclone warnings. Respondents who did not receive any warnings (17\% during Sidr and 7\% during Mahasen) also did not evacuate during the TCs. Compared to Bagerhat, the evacuation rate was greater among respondents in Patuakhali (67\% during Sidr, and 77\% during Mahasen).

According to the Comprehensive Disaster Management Program (CDMP) cyclone shelter information database, up to the year 2010, a total of 62 cyclone shelters have been constructed in Patuakhali and Bagerhat [21,71]. In Patuakhali, now 58\% of the respondents live within $1 \mathrm{~km}$ of a shelter. Despite this, $17 \%$ of the respondents in Patuakhali did not follow the evacuation orders during the two TCs, and additional $22 \%$ did not evacuate during one of the TCs. In Bagerhat, $57 \%$ of the respondents live within $1 \mathrm{~km}$ of a shelter, but $49 \%$ of the respondents did not follow the evacuation orders during the two TCs, and $31 \%$ did not follow the orders either during Sidr or during Mahasen.

Respondents who evacuated during both of the TCs were mostly from middle-sized families (having 4 to 6 family members) and had katcha houses. During Sidr, 82\% of those who evacuated in Bagerhat were from middle-sized families and $86 \%$ had katcha houses. Whereas among those who evacuated during Mahasen, $65 \%$ were from middle-sized families and $88 \%$ had katcha houses. Also in Patuakhali, those who evacuated were primarily from middle-sized families (67\% during Sidr and 70\% during Mahasen) and lived in katcha houses (97\% during Sidr and 94\% during Mahasen).

\subsubsection{Reasons for non-evacuation}

For identifying the key reasons for non-evacuation among the respondents and list these reasons according to their relative importance, we performed PCA on the reasons for nonevacuation that respondents gave in the questionnaire. The first five complex components (where component 1 is the most important and 5 is the least important) obtained through this analysis account for $70.728 \%$ of the variance of non-evacuation reasons during Sidr (Table 3 ). In other words, the PCA revealed the following top-five components of why residents did not evacuate during Sidr in Bagerhat:

1. Early warnings unreliable, later too far to go - aggregating the original variables:

- Mistrust in the warning messages

- Distance to the shelter

2. Need to protect property, while minimizing risk - aggregating the original variables:

- The closest shelter is in poor condition; therefore, the respondents had to travel longer distances for better shelters, which was not always a decision to make

- Sending family members to shelter, household head staying at home to protect the property

3. Unclear warning message, later on shelter is full-aggregating the original variables:

- Not understanding the instructions in the warning message

- Insufficient capacity of the nearest shelter

4. Feeling safe at home-aggregating the original variables: 
- Warning message indicates that the TC will not strike the home area

- The home being sufficiently robust

5. Insecurity - representing the original variable:

- Being afraid of residential burglary

In Bagerhat, the main reasons for non-evacuation during Mahasen were different. The PCA revealed the following top-four components, which explain $70.215 \%$ of the variance of non-evacuation reasons during Mahasen (Table 3):

1. Early warnings unreliable - representing the original variable:

- Mistrust in warning message

2. Unclear warning message, later too far to go-aggregating the original variables:

- Not understanding the instructions in the warning message

- Distance to shelter

3. Need to protect property, while minimizing risk-aggregating the original variables:

- Sending family members to shelter, family head staying at home to protect the property, and guessed that intensity of the TC will not be strong by looking at the surrounding situation

4. Difficulties with transportation - representing the original variable

- Poor road-transport conditions

Table 3 Components representing the causes of non-evacuation (extracted using PCA)

\begin{tabular}{|c|c|c|c|c|c|c|}
\hline \multicolumn{7}{|c|}{ Principal components representing the causes of non-evacuation in Bagerhat } \\
\hline \multirow[t]{2}{*}{ Component } & \multicolumn{3}{|c|}{$\begin{array}{l}\text { Extraction of the components } \\
\text { (During TC Sidr) }\end{array}$} & \multicolumn{3}{|c|}{$\begin{array}{l}\text { Extraction of the components } \\
\text { (During TC Mahasen) }\end{array}$} \\
\hline & Eigenvalue & $\begin{array}{c}\% \text { of } \\
\text { variance }\end{array}$ & $\begin{array}{l}\text { Cumulative } \\
\text { variance } \%\end{array}$ & Eigenvalue & $\begin{array}{c}\% \text { of } \\
\text { variance }\end{array}$ & $\begin{array}{l}\text { Cumulative } \\
\text { variance } \%\end{array}$ \\
\hline 1 & 1.705 & 17.052 & 17.052 & 1.856 & 23.200 & 23.200 \\
\hline 2 & 1.621 & 16.209 & 33.261 & 1.481 & 18.518 & 41.718 \\
\hline 3 & 1.363 & 13.630 & 46.891 & 1.246 & 15.573 & 57.291 \\
\hline 4 & 1.260 & 12.598 & 59.489 & 1.034 & 12.924 & 70.215 \\
\hline 5 & 1.124 & 11.239 & 70.728 & & & \\
\hline \multicolumn{7}{|c|}{ Principal components representing the causes of non-evacuation in Patuakhali } \\
\hline \multirow[t]{2}{*}{ Component } & \multicolumn{3}{|c|}{$\begin{array}{l}\text { Extraction of the components } \\
\text { (During TC Sidr) }\end{array}$} & \multicolumn{3}{|c|}{$\begin{array}{l}\text { Extraction of the components } \\
\text { (During TC Mahasen) }\end{array}$} \\
\hline & Eigenvalue & $\begin{array}{c}\% \text { of } \\
\text { variance }\end{array}$ & $\begin{array}{l}\text { Cumulative } \\
\text { variance } \%\end{array}$ & Eigenvalue & $\begin{array}{c}\% \text { of } \\
\text { variance }\end{array}$ & $\begin{array}{l}\text { Cumulative } \\
\text { variance } \%\end{array}$ \\
\hline 1 & 2.037 & 22.632 & 22.632 & 2.004 & 25.046 & 25.046 \\
\hline 2 & 1.705 & 18.941 & 41.573 & 1.274 & 15.919 & 40.966 \\
\hline 3 & 1.143 & 12.701 & 54.274 & 1.147 & 14.337 & 55.303 \\
\hline 4 & 1.062 & 11.801 & 66.075 & 1.025 & 12.812 & 68.115 \\
\hline 5 & 1.006 & 11.177 & 77.252 & & & \\
\hline
\end{tabular}

Note: Only eigenvalues greater $\geq 1$ are shown, while components having lower eigenvalues are excluded from the analysis. This entails that the cumulative variance explained by the principal components shown is less than $100 \%$. 
As described previously, the evacuation rate was higher among the respondents in Patuakhali (which is a high cyclone-risk area) compared to Bagerhat during both of the TCs. Of the total respondents, 67\% evacuated during Sidr and 77\% during Mahasen. The PCA revealed the following top-five components, which explain $77.252 \%$ of the variance of the non-evacuation reasons among the residents in Patuakhali during Sidr (Table 3):

1. Early warnings unreliable, later difficult to go far-aggregating the original variables:

- Mistrust in warning message

- Distance to shelter

- Poor road-transport

2. Unclear warning messages, need to protect property-aggregating the original variables:

- Not understanding the instructions in the warning message

- Being afraid of residential burglary

3. Minimizing risk-representing the original variable:

- Poor shelter condition

4. Feeling safe at home-representing the original reason:

- The home believed to be sufficiently robust

5. Need to protect property, while minimizing risk - aggregating the original variables:

- Sending family members to shelter, household head staying at home to protect the property, and all family members not wanting to go to shelter

The PCA revealed the following top-four components, which together explain $68.115 \%$ of the variance of the non-evacuation reasons during TC Mahasen (Table 3):

1. Early warnings unreliable, later difficult to go too far-aggregating the original variables:

- Mistrust in the warning message

- Distance to the shelter

- Poor road-transport

2. Insecurity, feeling safe at home - aggregating the original variables:

- Being afraid of residential burglary

- The home being sufficiently robust

3. Minimizing risk-representing the original variable:

- Insufficient accommodation capacity of the nearest cyclone shelter

4. Feeling safe at home - representing the original variable:

- Warning message indicates that the TC will not strike the home area

Each individual variable's (individual reason's) contribution to the aggregating principal components can be understood by looking at the variances that are explained by them (Table 4). Variables having high values are well represented by the principal components, whereas variables with low values are not well represented by the principal components.

Table 4 Individual non-evacuation reason's variance explained by the principal components

\begin{tabular}{|l|l|l|}
\hline $\begin{array}{c}\text { Non-evacuation reasons/original } \\
\text { variables }\end{array}$ & $\begin{array}{c}\text { Proportion of each non-evacuation reason's } \\
\text { variance that can be explained by the } \\
\text { principal components }\end{array}$ \\
\cline { 2 - 3 } & Among the residents in & Among the residents in \\
\hline
\end{tabular}




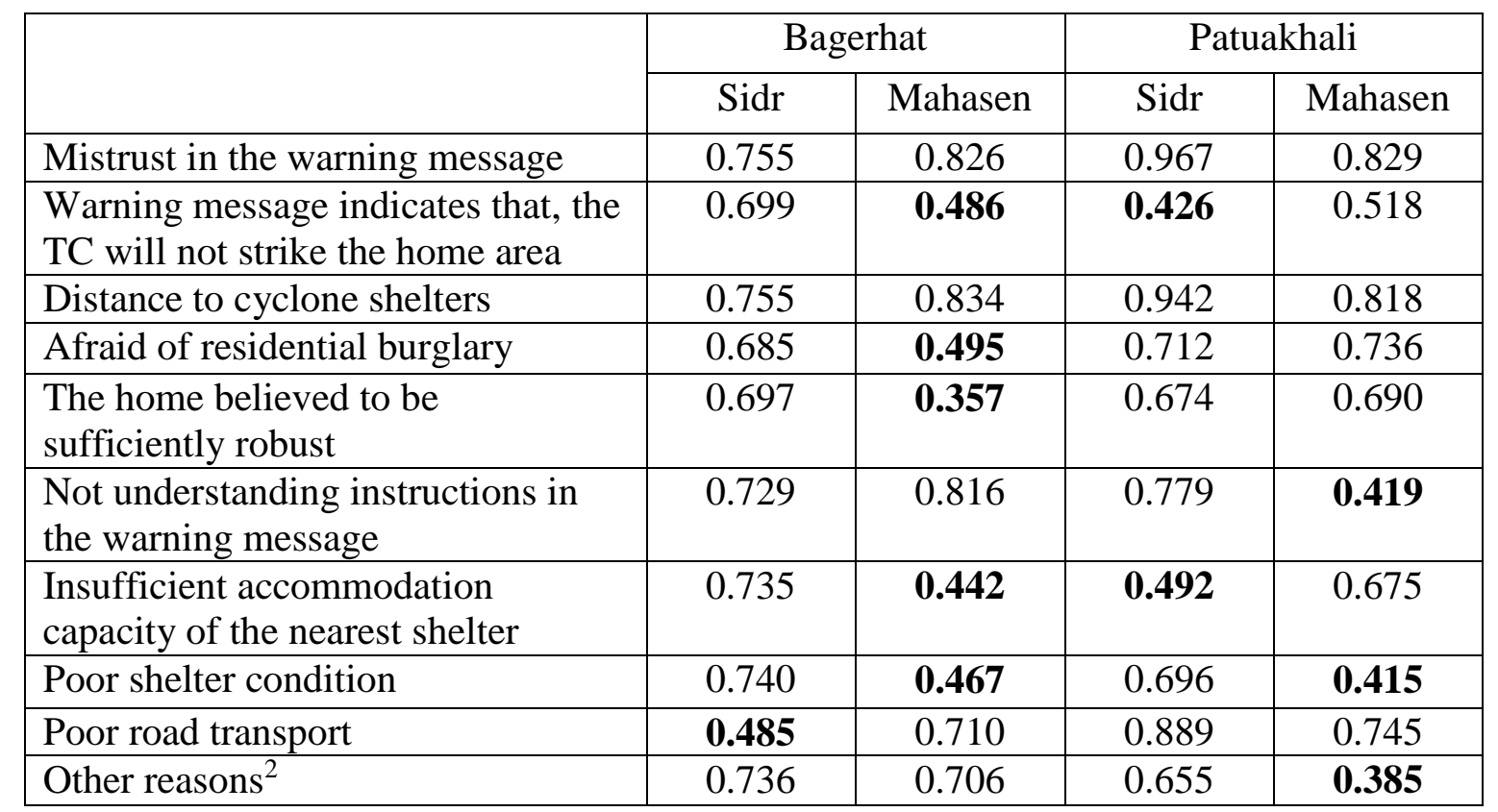

Note: To be included in the PCA, each factor (representing individual variable) should explain at least half of each original variable's variance. Therefore, values less than 0.50 (marked using boldface numbers) were excluded from the PCA.
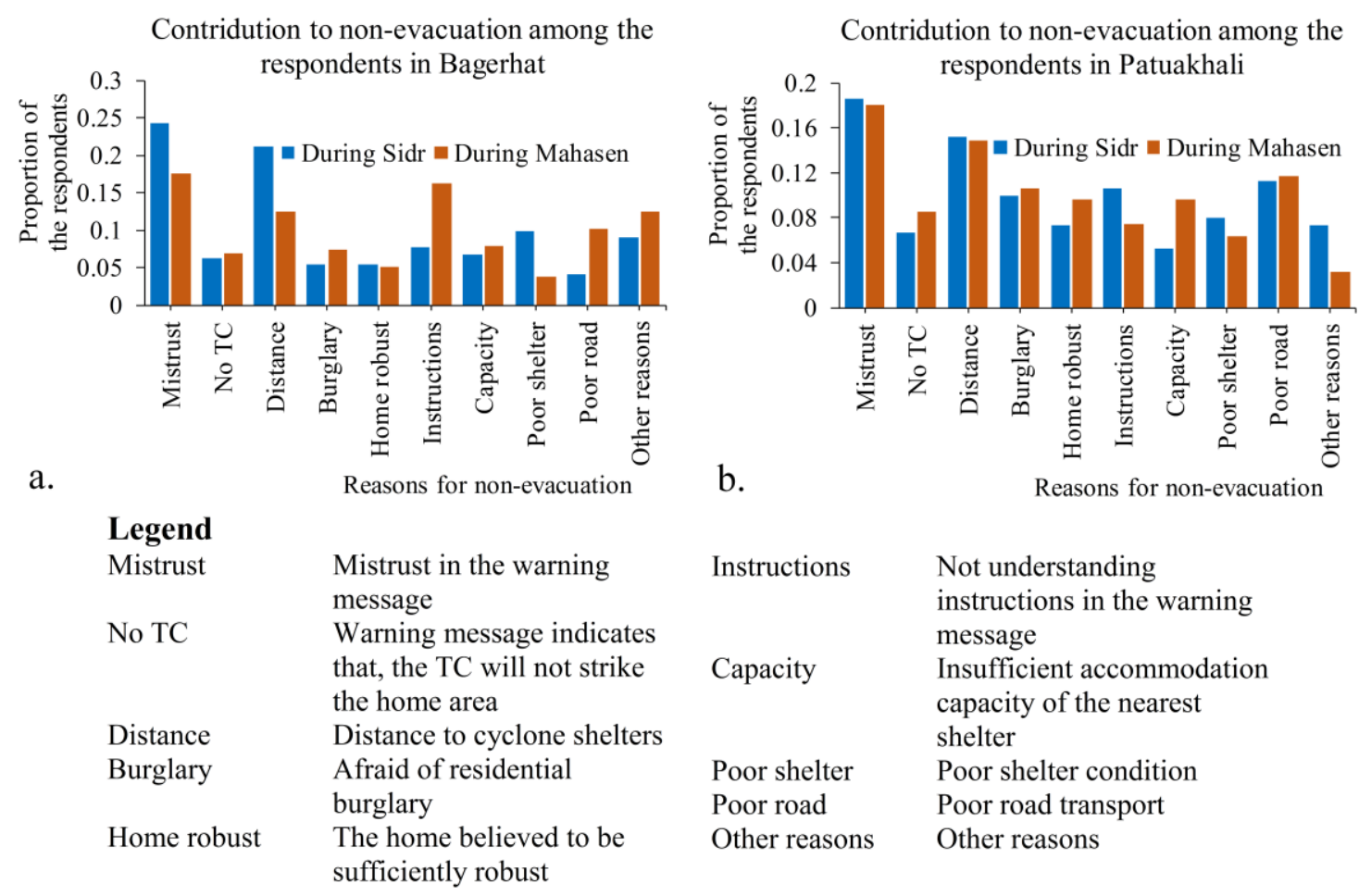

$\begin{array}{ll}\text { Instructions } & \begin{array}{l}\text { Not understanding } \\ \text { instructions in the warning } \\ \text { message }\end{array} \\ \text { Capacity } & \begin{array}{l}\text { Insufficient accommodation } \\ \text { capacity of the nearest } \\ \text { shelter }\end{array} \\ \text { Poor shelter } & \begin{array}{l}\text { Poor shelter condition } \\ \text { Poor road }\end{array} \\ \text { Other reasons } & \text { Other reasons }\end{array}$

Fig. 6. Individual reason's contribution to non-evacuation, a. among the respondents in Bagerhat, and b. among the respondents in Patuakhali. Frequencies in figures a. and $\mathbf{b}$. were obtained by dividing the participants' response for individual non-evacuation reason using the sum of responses for all non-evacuation reasons.

\footnotetext{
${ }^{2}$ These reasons include, sending family members to shelter, household head staying at home to save the property and/or guessed that intensity of the TC will not be strong by looking at the surrounding situation and/or all family members not wanting to go to shelter.
} 
The PCA that we performed revealed a number of principal components that aggregate several underlying variables. These principal components were ranked based on how much they explain of the variance of non-evacuation reasons that were given by the respondents. To complement this picture, and get an insight into how each individual reason contributed to non-evacuation, we present a frequency analysis in Fig. 6.

\subsection{Satisfaction with the warning messages and suggestions for improvement}

In Bagerhat, $50 \%$ of the respondents were satisfied with the warning messages at a very-high level (level 5), 35\% at high level, $9 \%$ at moderate level, $4 \%$ at low level, while $2 \%$ were dissatisfied (level 1). This result suggests that most of the respondents in Bagerhat were satisfied with the disseminated warnings. For them, the reasons for being satisfied with the warnings were: $80 \%$ found it easily understandable, $70 \%$ found it timely, $61 \%$ found it dependable, and $45 \%$ stated claimed them as the only option for getting information about the approaching TC in an emergency situation (multiple responses were possible).

In Patuakhali, 53\% the respondents were satisfied with the warning messages at a veryhigh level, $32 \%$ at high level, $12 \%$ at moderate level, and 3\% at low level. Therefore, the respondents were in general satisfied with the disseminated warnings, except the $15 \%$ moderate and low satisfied respondents. As for the reasons for being satisfied, $85 \%$ of the respondents claimed the warning messages to be understandable, $73 \%$ claimed them timely, $58 \%$ claimed them dependable, and $49 \%$ claimed them as the only option for getting information about the approaching TC (multiple responses were possible).

Among all the respondents in the survey, the reasons for moderate or low level of satisfaction, or dissatisfaction with the warning messages were: (a) the warnings were false and/or (b) the warnings contained insufficient information so it was difficult to decide whether to evacuate or not. During the survey, the respondents were asked to express their opinion on how warning messages could be further improved in the future. In Bagerhat, $68 \%$ of the respondents answered that future warning messages could be improved in the following ways (multiple responses were possible):

1. $57 \%$ recommended the inclusion of better description of the threat, such as the certainty of the TC making landfall, how urgently the residents should take protective action, and the duration of the intense cyclonic wind.

2. $43 \%$ recommended the inclusion of guidance on where to get further information about the approaching TC.

3. $26 \%$ recommended the inclusion of guidance on protective action (what the residents should do to protect themselves from a TC).

In Patuakhali, 92\% of the respondents suggested the following improvements to future warning messages (multiple responses were possible):

1. $85 \%$ recommended the inclusion of better description of the threat.

2. $54 \%$ recommended the inclusion of guidance on where to get further information about the approaching TC.

3. $29 \%$ recommended the inclusion of guidance on protective action. 


\section{Discussion of non-evacuation reasons}

The PCA that we performed on the results reveals a number of complex reasons for nonevacuation among residents. The main complex reasons seems to concern a basic uncertainty at the early stage of a cyclone emergency: Will the cyclone hit this particular area, and how severe will the cyclone be? Uncertain forecasts, and unclear cyclone warning contents can prevent residents from taking protective and preparatory actions at an early stage, with a large proportion of the residents deciding not to take any actions until more (reliable) information becomes available.

As an alternative to early evacuation, a proportion of the residents seem to compromise, by taking some preparatory actions, and by sending some family member to a shelter, while having at least one family member staying at home. These residents seem to try to minimize all risks, with focus on the risk for burglary, and the risk that unnecessary preparatory work is performed (and valuable working hours are lost).

At a later stage of the cyclone emergency, the informational basis for a decision whether to evacuate or not tend to be more reliable, due to easier TC forecasts as the TC is approaching land. However, at this late stage, the cyclone may have approached land, leaving very short time for evacuation. Hence, at this late stage, other concerns may be prominent in decision making, such as if there is enough time to reach a far-located shelter, and if the shelter will already be full.

\subsection{Individual reasons for non-evacuation}

While the set of main reasons seems to be similar among the respondents, the relative order of individual reasons for non-evacuation in the two study areas differs. The motives for respondents' prioritizing different reasons for non-evacuation seem to be associated with:

1. Respondents' view of risk. The two studied unions of Patuakhali directly borders with the sea, whereas the Sundarbans works as a natural barrier between the two studied unions of Bagerhat and the sea. Therefore, respondents in Bagerhat are less exposed to TCs compared to respondents in Patuakhali. Moreover, due to the movement pattern of TCs in the bay, TCs frequently make landfall at the mid and the east coast of Bangladesh [18], which means that Patuakhali is more exposed to TCs compared to Bagerhat. These variations in the degree of exposure to TCs might have motivated the respondents to hold different views of risk and act differently during the studied TCs.

2. Respondents' socio-economic status. The socio-economic status of the respondents in the two selected districts was almost the same. However, the small variations that we elicited through the questionnaire survey might have created dissimilar problems among the respondents in making decision for evacuation.

3. Availability and/or condition of the infrastructures, such as cyclone shelters, roads, and the houses the respondents live in.

\section{Discussion}

The TC early warning system in Bangladesh as well as the coastal residents' response to warning messages has been the focus of a large number of studies conducted during the last two decades. The reasons for non-evacuation identified in the present study are in line with previously acknowledged reasons for non-evacuation [4,7-9,14,36-39,72-74]. Additionally, 
the present study complements earlier research by highlighting the importance of the technical difficulties of TC forecasting at BMD, and the key role that the contents of cyclone warning messages play for residents' evacuation behavior. It seems particularly important that the residents can perceive the contents of warning messages as trustworthy.

It is essential for residents that the warnings they receive are reliable in order for them to take necessary action. On $14^{\text {th }}$ of November 2007, BMD issued seven special weather bulletins (special bulletin sl. no. 13 to 19). While in bulletins 13-17, the forecasted danger levels for both of the maritime ports Mongla and Chittagong were 4 (wind speeds between 51 $\mathrm{km} / \mathrm{h}$ and $61 \mathrm{~km} / \mathrm{h}$ ), in bulletin 18 the danger level was suddenly changed from 4 to 10 (wind speed $\geq 171 \mathrm{~km} / \mathrm{h}$ ) for the Mongla maritime port, and from 4 to 9 (wind speeds between 118 $\mathrm{km} / \mathrm{h}$ and $170 \mathrm{~km} / \mathrm{h}$ ) for the Chittagong maritime port [63]. When residents experience such a large variation between two consecutive warnings, it is not surprising that they tend to loose trust in the warning messages.

Moreover, insufficient information about TC landfall in the warning messages can make the decision for evacuation difficult for the residents. We would like to quote one sentence from the special weather bulletin sl. no. 25 issued on $15^{\text {th }}$ of November 2007: "Cyclone Sidr is likely to intensify further and move in a northerly direction and cross the Khulna-Barisal coast by today evening". During the dissemination of this special bulletin, TC Sidr was only $265 \mathrm{~km}$ away to the south of Mongla maritime port. In spite of this, BMD did not indicate the approximate time (in hours) and the approximate location of landfall in the warning message.

The reasons for the dissemination of unreliable and uninformative warning messages by BMD appear to be related to: (a) incomplete data used for forecasting TC track and intensity, and (b) limitations of the operational TC forecasting technique itself. BMD has access to ocean buoy data and atmospheric reanalysis data, and these could be used for producing good quality forecasts. However, these data cannot be used by the meteorologists for improving forecast quality due to data format limitations associated with the operational TC forecasting technique. Conversely, although BMD has access to numerical forecasting techniques which are open to the use of ocean buoy and atmospheric reanalysis data, these techniques have originally been developed for general meteorological phenomena, and the meteorologists at BMD do not have the necessary skills to modify these numerical techniques and adapt them for forecasting TCs.

Residents' not following the evacuation orders although they live within $1 \mathrm{~km}$ of a shelter and instead optimistically following a "wait and see" strategy [31,74,75], highlight the issue of mistrust in the warnings and difficulty to understand the instructions contained in the warnings, along with other reasons for non-evacuation. Although most of the respondents in the selected unions claim the warning messages to be understandable, the rate of correct warning message interpretation among the respondents reveal inappropriate understanding of the instructions conveyed in the warnings. The dissemination of imprecise and uninformative warning messages by BMD seems to cause mistrust, as well as difficulty to understand the instructions in the warnings among the respondents. Respondents' suggestions for improving future warnings also reflect BMD's insufficient ability to disseminate informative and reliable warning messages.

For improved cyclone preparedness and for eliciting expected response to evacuation orders from the residents, the Bangladesh government, in cooperation with supporting 
countries and organizations, has initiated large-scale projects for infrastructural development in the coastal areas during the recent years [76]. In addition, the government and supporting organizations have taken initiatives to increase the residents' response capacity to evacuation orders as well as to enhance their capability for coping with TCs in the coastal areas [77-79]. However, in view of our results, it is unfortunate that improving BMD's TC forecasting ability has not received adequate attention in the national cyclone emergency preparedness plan [21], and no strategic goal has been set by the government for the development of BMD in the national plan for disaster management 2010-2015 [80]. As a net result, BMD is still today forecasting TCs using techniques that are only accurate for the next 12 hours, and disseminating warning messages based on these forecasts.

\section{Conclusions}

This study examined the processes of TC forecasting and warning at BMD, as well as coastal residents' response patterns to the warnings issued before the landfall of TCs Sidr and Mahasen. Due to its geographical location, Patuakhali is generally more exposed to TCs than Bagerhat. This higher exposure ought to have motivated the residents of Patuakhali to follow the information contained in the warning messages and to act accordingly to a larger extent than residents in Bagerhat. Nonetheless, although a large percentage of the residents were reached by the warnings and knew the potential consequences of non-evacuation, many of the residents in both study areas did not take necessary protective measures during cyclones Sidr and Mahasen. Our results indicate that this seems to be mainly due to mistrust in the warning messages, and not understanding the instructions conveyed in the warning messages. Other practical concerns include insufficient number of cyclone shelters and poor road conditions.

On the technical side, producing good-quality forecasts for longer time periods ( 24 hours or longer) is a precondition for delivering a timely, reliable, and informative warning, and this seems not possible until good quality data is used and the operational forecasting techniques at BMD are replaced with more capable techniques. The introduction of a new unified eight-point signaling system could help the residents understand the danger level. Also, the recently developed warning dissemination methods could help reach a larger percent of the population. However, the contents of the warning messages, as well as residents' trust and response to warnings would remain the same until BMD can improve the quality of TC forecasts and formulate and disseminate warnings based on those higherquality forecasts.

\section{Acknowledgements}

The authors thank Badal Biswas and Mehedi Hassan for their assistance with the surveys.

\section{References}

[1] M.A. Khan, I.A. Bhuyan, M.M. Rahman, Assessment of Cyclone Risk under the Changing Climatic Condition for the Coastal Areas of Bangladesh, in: Northumbria University, UK, 2010.

[2] MWR (Ministry of Water Resources), Coastal Zone Policy, Dhaka, Bangladesh, 2005.

[3] BBS (Bangladesh Bureau of Statistics), Bangladesh Population \& Housing Census 2011, Dhaka, Bangladesh, 2012. 
[4] U. Haque, M. Hashizume, K. Kolivras, H.J. Overgaard, B. Das, T. Yamamoto, Reduced death rates from cyclones in Bangladesh: what more needs to be done?, Bull. World Health Organ. 90 (2012) 150-156. doi:10.2471/BLT.11.088302.

[5] B.K. Paul, Why relatively fewer people died? The case of Bangladesh's Cyclone Sidr, Nat. Hazards. 50 (2009) 289-304.

[6] B.K. Paul, H. Rashid, M.S. Islam, L.M. Hunt, Cyclone evacuation in Bangladesh: Tropical cyclones Gorky (1991) vs. Sidr (2007), Environ. Hazards. 9 (2010) 89-101.

[7] B.K. Paul, S. Dutt, Hazards warnings and response to evacuation orders: The case of Bangladesh's cyclone Sidr, Geogr. Rev. 100 (2010) 336-355. doi:10.1111/j.19310846.2010.00040.x.

[8] C.E. Haque, Atmospheric Hazards Preparedness in Bangladesh: A Study of Warning, Adjustments and Recovery from the April 1991 Cyclone, Nat. Hazards. 16 (1997) 181202.

[9] S.K. Paul, J.K. Routray, Household response to cyclone and induced surge in coastal Bangladesh: coping strategies and explanatory variables, Nat. Hazards. 57 (2011) 477499. doi:10.1007/s11069-010-9631-5.

[10] T.E. Drabek, Understanding disaster warning responses, Soc. Sci. J. 36 (1999) 515-523. doi:10.1016/S0362-3319(99)00021-X.

[11] T.E. Drabek, Human system responses to disaster: an inventory of sociological findings, Springer-Verlag, 1986.

[12] D. Parker, Criteria for evaluating the condition of a tropical cyclone warning system, Disasters. 23 (1999) 193-216.

[13] WMO (World Meteorological Organisation), Human Response to Tropical Cyclone Warnings and their Content, World Meteorological Organisation, Geneva, 1989.

[14] M.H. Akhand, Disaster Management and Cyclone Warning System in Bangladesh, in: J. Zschau, A. Küppers (Eds.), Early Warn. Syst. Nat. Disaster Reduct., Springer Berlin Heidelberg, 2003: pp. 49-64. http://link.springer.com/chapter/10.1007/978-3-64255903-7_8 (accessed March 30, 2014).

[15] G.O.P. Obasi, WMO's Role in the International Decade for Natural Disaster Reduction, Bull. Am. Meteorol. Soc. 75 (1994) 1655-1661. doi:10.1175/15200477(1994)075<1655:WRITID>2.0.CO;2.

[16] RSMC (Regional Specialized Meteorology Centers), New Delhi, Report on cyclonic disturbances over North Indian Ocean, New Delhi, 2013.

[17] ADRC (Asian Disaster Reduction Center), Total disaster risk management - good practice, Kobe, Japan, 2005.

[18] S.K. Debsarma, Cyclone forecasting and its constraints for the Bay of Bengal, in: SMRC, Dhaka, 1999: p. 7.

[19] W.M. Gray, Global view of the origin of tropical disturbances and storms, Mon Wea Rev. 96 (1968) 669-700.

[20] M. Shamsuddoha, R.K. Chowdhury, Climate change impact and disaster vulnerabilities in the coastal areas of Bangladesh, COAST Trust Dhaka. (2007) 32.

[21] DDM (Department of Disaster Management), Emergency Preparedness Plan for Cyclone Bangladesh, Dhaka, Bangladesh, 2013.

[22] DMB (Disaster Management Bureau), Standing Orders on Disaster, Dhaka, Bangladesh, 2010.

[23] S.K. Debsarma, Cyclone and Its Warning System in Bangladesh, in: Dhaka, Bangladesh, 2001: p. 17.

[24] DDM (Department of Disaster Management), New signaling system for cyclone and disaster message for public (original in bengali), Ministry of Food and Disaster Management, Dhaka, Bangladesh, 2009. 
[25] G. Klein, Naturalistic Decision Making, Hum. Factors J. Hum. Factors Ergon. Soc. 50 (2008) 456-460. doi:10.1518/001872008X288385.

[26] G.A. Klein, R. Calderwood, Decision models: some lessons from the field, IEEE Trans. Syst. Man Cybern. 21 (1991) 1018-1026. doi:10.1109/21.120054.

[27] P. Slovic, M.L. Finucane, E. Peters, D.G. MacGregor, Risk as Analysis and Risk as Feelings: Some Thoughts about Affect, Reason, Risk, and Rationality, Risk Anal. 24 (2004) 311-322. doi:10.1111/j.0272-4332.2004.00433.x.

[28] J.L. McClelland, On the time relations of mental processes: An examination of systems of processes in cascade, Psychol. Rev. 86 (1979) 287-330. doi:10.1037/0033295X.86.4.287.

[29] E.L. Quarantelli, People's reactions to emergency warning, in: Artic. 170, Disaster Research Center, University of Delaware, University of Charleston, West Virginia, 1983: pp. 176-187. http://udspace.udel.edu/handle/19716/452 (accessed October 23, 2014)

[30] E.L. Quarantelli, The Warning Process And Evacuation Behavior: The Research Evidence, (1990). http://dspace.udel.edu:8080/dspace/handle/19716/520 (accessed March 29, 2011).

[31] E. Alam, A.E. Collins, Cyclone disaster vulnerability and response experiences in coastal Bangladesh, Disasters. 34 (2010) 931-954. doi:10.1111/j.14677717.2010.01176.x.

[32] N. Dash, H. Gladwin, Evacuation decision making and behavioral responses: Individual and household, Nat. Hazards Rev. 8 (2007) 69.

[33] H. Gladwin, J.K. Lazo, B.H. Morrow, W.G. Peacock, H.E. Willoughby, Social science research needs for the hurricane forecast and warning system, Nat. Hazards Rev. 8 (2007) 87.

[34] A.A. Rahman, M. Alam, S.S. Alam, R. Uzzaman, M. Rashid, G. Rabbani, Risks, Vulnerability and Adaptation in Bangladesh: Occasional paper on human development, BCAS, Dhaka, Bangladesh, 2007.

[35] B.K. Paul, Factors Affecting Evacuation Behavior: The Case of 2007 Cyclone Sidr, Bangladesh, Prof. Geogr. 64 (2012) 401-414. doi:10.1080/00330124.2011.609780.

[36] A. Paul, M. Rahman, Cyclone Mitigation Perspectives in the Islands of Bangladesh: A Case of Sandwip and Hatia Islands, Coast. Manag. 34 (2006) 199-215. doi:10.1080/08920750500531371.

[37] M.S. Islam, M.S. Ullah, A. Paul, Community Response to Broadcast Media for Cyclone Warning and Disaster Mitigation: A Perception Study of Coastal People with Special Reference to Meghna Estuary in Bangladesh, Asian J. Water Environ. Pollut. 1 (2004) $55-64$.

[38] A. Asgary, A. Halim, Measuring people's preferences for cyclone vulnerability reduction measures in Bangladesh, Disaster Prev. Manag. Int. J. 20 (2011) 186-198. doi:10.1108/09653561111126111.

[39] B. Mallick, S.M. Witte, R. Sarkar, A.S. Mahboob, J. Vogt, Local Adaptation Strategies of a Coastal Community during Cyclone Sidr and their Vulnerability Analysis for Sustainable Disaster Mitigation Planning in Bangladesh, J. Bangladesh Inst. Plan. 2 (2009) 158-168. doi:10.3329/jbip.v2i0.9576.

[40] B.J. Brady, Hurricane forecasting and warning system, NCAR, California, 2005. http://www.sip.ucar.edu/pdf/Hurricane_Forecasting_and_Warning_System_Report.pdf.

[41] D. Parker, M. Fordham, An evaluation of flood forecasting, warning and response systems in the European Union, Water Resour. Manag. 10 (1996) 279-302. doi:10.1007/BF00508897. 
[42] E.J. Baker, Hurricane evacuation behavior, Int. J. Mass Emergencies Disasters. 9 (1991) 287-310.

[43] E.J. Baker, Predicting response to hurricane warnings: A reanalysis of data from four studies, Mass Emergencies. 4 (1979) 9-24.

[44] J.K. Riad, F.H. Norris, R.B. Ruback, Predicting Evacuation in Two Major Disasters: Risk Perception, Social Influence, and Access to Resources, J. Appl. Soc. Psychol. 29 (1999) 918-934. doi:10.1111/j.1559-1816.1999.tb00132.x.

[45] H.V.D. Berg, M. Wetherell, H. Houtkoop-Steenstra, eds., Analyzing Race Talk: Multidisciplinary Perspectives on the Research Interview, Cambridge University Press, 2003.

[46] C. Boyce, P. Neale, Conducting in-depth interviews: A guide for designing and conducting in-depth interviews for evaluation input, Pathfinder International Watertown, MA, 2006. http://www.cpc.unc.edu/measure/training/materials/data-qualityportuguese/m_e_tool_series_indepth_interviews.pdf (accessed July 24, 2014).

[47] L.A. Guion, D.C. Diehl, D. McDonald, Conducting an in-depth interview, (2011). http://edis.ifas.ufl.edu/fy393 (accessed October 22, 2014).

[48] R. Legard, J. Keegan, K. Ward, In-depth interviews, Qual. Res. Pract. Guide Soc. Sci. Stud. Res. (2003) 138-169.

[49] N.M. Bradburn, S. Sudman, B. Wansink, Asking Questions: The Definitive Guide to Questionnaire Design -- For Market Research, Political Polls, and Social and Health Questionnaires, John Wiley \& Sons, 2004.

[50] D. Guha-Sapir, M.F. Lechat, Information systems and needs assessment in natural disasters: an approach for better disaster relief management, Disasters. 10 (1986) 232237.

[51] T. Kurita, A. Nakamura, M. Kodama, S.R. Colombage, Tsunami public awareness and the disaster management system of Sri Lanka, Disaster Prev. Manag. 15 (2006) 92-110.

[52] R. Shaw, K.S.H. Kobayashi, M. Kobayashi, Linking experience, education, perception and earthquake preparedness, Disaster Prev. Manag. 13 (2004) 39-49.

[53] V. Braun, V. Clarke, Using thematic analysis in psychology, Qual. Res. Psychol. 3 (2006) 77-101. doi:10.1191/1478088706qp063oa.

[54] J. Fereday, E. Muir-Cochrane, Demonstrating Rigor Using Thematic Analysis: A Hybrid Approach of Inductive and Deductive Coding and Theme Development, Int. J. Qual. Methods. 5 (2008) 80-92.

[55] R.E. Boyatzis, Transforming qualitative information: Thematic analysis and code development, Sage, 1998.

[56] RAMMB (Regional and Mesoscale Meteorology Branch, NOAA), Real-Time Tropical Cyclone Products, (2011). http://rammb.cira.colostate.edu/products/tc_realtime/ (accessed April 10, 2011).

[57] Y.D. Edwards, G.M. Allenby, Multivariate Analysis of Multiple Response Data, J. Mark. Res. 40 (2003) 321-334. doi:10.1509/jmkr.40.3.321.19233.

[58] J.R.A. Santos, Getting the most out of multiple response questions, ACE. 2 (2000) 1-4.

[59] T.D. Keenan, A diagnostic study of tropical cyclone forecasting in Australia, Aust Met Mag. 30 (1982) 69-80.

[60] R.A. Jeffries, C.R. Sampson, L.E. Carr III, J.H. Chu, Tropical Cyclone Forecasters Reference Guide. 5. Numerical Track Forecast Guidance, NRL, Monterey, CA, 1993. http://handle.dtic.mil/100.2/ADA277318 (accessed September 30, 2012).

[61] C.J. Neumann, An alternative to the HURRAN (hurricane analog) tropical cyclone forecast system, NHC, Miami, Florida, 1972.

[62] I. Roulstone, J. Norbury, Invisible in the Storm: The Role of Mathematics in Understanding Weather, Princeton University Press, 2013. 
[63] SWC (Storm warning Center), Tropical Cyclone Sidr Warning Message, (2007).

[64] SWC (Storm warning Center), Tropical Cyclone Mahasen Warning Message, (2013).

[65] E. Kalnay, M. Kanamitsu, R. Kistler, W. Collins, D. Deaven, L. Gandin, et al., The NCEP/NCAR 40-Year Reanalysis Project, Bull. Am. Meteorol. Soc. 77 (1996) 437471. doi:10.1175/1520-0477(1996)077<0437:TNYRP>2.0.CO;2.

[66] N. NOAA, NHC Track and Intensity Models, (2012). http://www.nhc.noaa.gov/modelsummary.shtml (accessed November 19, 2014).

[67] C. Roy, R. Kovordányi, Tropical cyclone track forecasting techniques - A review, Atmos Res. 104-105 (2012) 40-69. doi:10.1016/j.atmosres.2011.09.012.

[68] C. Roy, R. Kovordányi, Tropical Cyclone Track Forecasting, in: Encycl. Nat. Hazards, Taylor \& Francis Group, 2015.

[69] A. Simmons, S. Uppala, D. Dee, S. Kobayashi, ERA-Interim: New ECMWF reanalysis products from 1989 onwards, ECMWF Newsl. 110 (2007) 25-35.

[70] S. Gopalakrishnan, Q. Liu, T. Marchok, D. Sheinin, N. Surgi, M. Tong, et al., Hurricane Weather Research and Forecasting (HWRF) model: 2011 scientific documentation, Bernardet Ed. (2011).

http://www.dtcenter.org/HurrWRF/users/docs/scientific_documents/HWRFScientificDo cumentation_August2011.pdf (accessed November 17, 2013).

[71] M. of D.M. and R., Bangladesh CDMP, Cyclone Shelter Information Database, (2010). http://www.dmic.org.bd/csdb/ (accessed November 14, 2014).

[72] C.E. Haque, Climatic hazards warning process in Bangladesh: experience of, and lessons from, the 1991 April cyclone, Environ. Manage. 19 (1995) 719-734.

[73] P. Howell, Indigenous early warning indicators of cyclones: potential application in coastal Bangladesh, Benfield Greig Hazard Research Centre, London, 2003. http://www.unisdr.org/files/1529_workingpaper6.pdf (accessed October 23, 2014).

[74] A.M.R. Chowdhury, A.U. Bhuyia, A.Y. Choudhury, R. Sen, The Bangladesh Cyclone of 1991: Why So Many People Died, Disasters. 17 (1993) 291-304. doi:10.1111/j.14677717.1993.tb00503.x.

[75] C. Bern, J. Sniezek, G.M. Mathbor, M.S. Siddiqi, C. Ronsmans, A.M. Chowdhury, et al., Risk factors for mortality in the Bangladesh cyclone of 1991., Bull. World Health Organ. 71 (1993) 73.

[76] The World Bank, Emergency Cyclone Recovery and Restoration Project, (2013). http://www.worldbank.org/projects/P111272/emergency-2007-cyclone-recoveryrestoration-project?lang=en (accessed April 8, 2014).

[77] F. Thomalla, T. Cannon, S. Huq, R.J. Klein, C. Schaerer, Mainstreaming adaptation to climate change in coastal Bangladesh by building civil society alliances, Solut. Coast. Disasters. (2005) 668-684.

[78] M.R. Khan, M.A. Rahman, Partnership approach to disaster management in Bangladesh: a critical policy assessment, Nat. Hazards. 41 (2007) 359-378.

[79] N. Matin, M. Taher, The changing emphasis of disasters in Bangladesh NGOs, Disasters. 25 (2001) 227-239.

[80] DMB (Disaster Management Bureau), National Plan for Disaster Management 20102015, Dhaka, Bangladesh, 2010. 